\title{
An Application of Cultural Models Theory to Cross-cultural Awareness Cultivation in Primary School English Teaching
}

\begin{abstract}
Xin Ma
School of Foreign Languages and Literatures, Chongqing Normal University, Chongqing, China

Abstract - Cultural models theory is one of the most important theories in cognitive linguistics. This paper briefly introduces the theory of cultural models in cognitive linguistics, analyses the current situation of cross-cultural awareness teaching in primary school, and further discusses the significance of cultural models theory in the cultivation of cross-cultural awareness in primary school English teaching. This theory provides a tool for teachers to cultivate pupils' cross-cultural awareness, so teachers can effectively introduce cultural factors into primary school English teaching.
\end{abstract}

Index Terms - culture, cultural models, primary school, English teaching

\section{INTRODUCTION}

With the vigorous development of the integration of global economy, closer connections between countries lead to more importance of the communication between nations. Therefore, in primary school, it is of great importance to train pupils to foster cross-cultural awareness and sensitivity to cultural differences, shorten cultural gaps, and develop cross-cultural communication competence.

With the influence of the integration of global, the countries are linked to each other closely. The communication between different countries is becoming more and more important. Therefore, it is urgent to cultivate students to have a sense of cross-cultural awareness. However, the traditional primary English teaching is too circumstanced, and fails to cultivate students to have a sense of cross-cultural awareness. Cultural models theory is effective and useful in training students to have a sense of cross-cultural awareness and become globalized.

The paper starts with the analysis of the theory of cultural models, exploring the effects of cultural models on the training of students to form cross-cultural awareness. The paper consists of the theory and characteristics of cultural models, and analyzes the advantages of the cultural models on the cultivation of cross-cultural awareness of the primary school students. The paper firstly analyzes the theory and background of cultural models, and then, the paper analyzes present situation of primary school teaching, which presents some advantages of cultural models. Finally, the paper summarizes how to apply cultural models to primary English teaching.

\section{THEORETICAL FRAMEWORK}

This part mainly discusses the related theories in order to lay a solid foundation for the smooth implement of theories. Besides, these theories will provide a theoretical support for the application of cultural models theory.

\section{A. English Curriculum Standards for Compulsory Education}

According to the 2011 National English Curriculum: "the general objectives of the English curriculum for nine-year compulsory education is to train the students to have the comprehensive language ability, which consists of five parts, that are language knowledge, language skills, affect, learning strategies, and cultural awareness. Cultural awareness is good for understanding language correctly and using language appropriately" (English Curriculum Standards, 2011). Therefore, one of the ultimate goals of English teaching is to train students to have cross-cultural awareness.

The general objective of English Curriculum Standards for Compulsory Education in 2011 includes five aspects: language skills, language knowledge, affect, learning strategies and cultural awareness. Among them, "the objective of cultural awareness in the initial stage is that students will have a rough understanding of the similarities and differences between Chinese and foreign cultures, and then in the higher stage of English learning, students can improve the sensitivity and appreciating ability of Chinese and foreign cultural similarities and differences, and developing cross-cultural awareness" (English Curriculum Standards, 2011).

\section{B. Cultural Models Theory}

"Cultural model theory is one of the most important theories in cognitive anthropology today" (Chen, 2017). Furthermore, "Cognitive models represent a cognitive view of the stored knowledge about a certain field. The description of cognitive models is based on the assumption that many people have roughly the same basic knowledge 
about many things" (Xu, 2003). But cognitive models are not universal, because cognitive models for particular domains ultimately depend on so-called cultural models. "Cultural models can be seen as cognitive models that are be shared by people belonging to a social group or subgroup" (F. Ungerer\&H.-J. Schmid, 2008).

Cognitive models and cultural models are two sides of the same coin. However, "cognitive model stresses the psychological nature of these cognitive entities and allows for inter-individual differences, cultural model emphasizes the uniting aspect of been collectively shared by many people. Although cognitive models are related to cognitive linguistics and psycholinguistics while cultural models belong to sociolinguistics and anthropological linguistics. Researches usually are aware of both dimensions of their object of study" (F. Ungerer\&H.-J. Schmid, 2008).

\section{Present Situation of Cultural Awareness Training in Primary School}

\section{A. Existing Problems}

The advantages of training the cultural awareness of the pupils have been discussed. Do Chinese students acquire cultural knowledge while learning? This part mainly discusses the present situation of English teaching, especially primary school English teaching.

In China, most students start to learn English in the third grade of primary school, therefore, students learn English for four years in primary school, and six years in junior high school and four years in university. That is to say, most Chinese students learn English for 14 years. Due to some uncontrollable factors, for a small number of primary school students who do not receive English courses, time of English learning is at least 10 years. For such a long period of study, it is reasonable that Chinese students should be adequately proficient in English learning. However, most students' learning of English is generally regarded as incomplete. Many Chinese students can't read efficiently and write correctly, let alone talk directly with the local people. Some people even criticize that English teaching in China is "deaf-and-dumb", not only because of large number of Chinese students pay little attention to English listening and English speaking, but also for the difficulties of overcoming English listening and speaking. Even for some students who have a good command of English, communication failures and misunderstandings will occur from time to time. The reason is obvious that it is mainly due to the inadequate understanding of different cultures.

The lack of formal cultural learning is also an important reason. For every English learner, it is commonly accepted that cultural knowledge of the conventions, beliefs, customs, and systems of meaning of another country is an integral part of foreign language learning. But in spite the fact that the importance of cultural awareness training has been stressed by many educators, attention that has been given to cultural factors in language teaching classrooms is far from enough. Cultural awareness is seldom mentioned in classroom English teaching, or just mentioned, but almost never been trained systematically. One of the reasons is that students in China should pass the grammar-oriented examinations. "In order to get students to pass the many exams they must take, many EFL teachers strive to provide the grammatical and vocabulary knowledge" (J. Penner, 1995). As a result, culture awareness training of English in China is not only sporadic but also insubstantial.

\section{B. Cases of Cultural Misunderstanding}

\section{Case 1}

Our oral English teacher John is from New Zealand and what he often says in class is: "culture is not right, not wrong, it's just different". For instance, compared with John, we have different cognition of a good composition. In our opinion, a good composition must contain subordinate clause, multiple sentences, complicated words and conjunctions. However, John strongly advised us to write passages with simple sentences and simple words, avoiding using complicated words, and just make our opinions easily understood, and just make passages clearly understood.

Analysis: This case mainly illustrates that Chinese students usually learn English as second language in the process of English learning. Therefore, in the evaluation of English writing, the vocabulary, phrases and sentence patterns used by students will be regarded as one of the important criteria for the quality of composition by teachers. However, in British and American countries, English is the first language in the process of students' learning. Therefore, in the part of writing, students are usually required to be able to express their meaning just by simple words, and there is not much demand for vocabulary.

Case 2

When Date with friends, Chinese people generally express friendship and respect for you in advance. Sometimes they say, "I've been waiting for you for three days. I finally saw you today". But it's different in foreign countries. For example, if they date at 9 o'clock. Often, just after the clock strikes 9 o'clock, the foreigner comes out and says, "Hello, I'm on time".

Analysis: This case tells us that Chinese and foreigners have different dating cultures. In China, in order to show respect, some friends often choose to arrive long before the meeting time when they go out with friends. However, foreigners seldom go to the place of appointment long in advance when they are on a date, and they prefer to arrive at the place of appointment on time.

Case 3

In 1992, a delegation of 13 experts from different professions in China went to a western country to purchase about 30 million dollars of chemical equipment and technology. Naturally, the businessmen have tried every means to satisfy 
the experts. One of them is to give each of experts a small souvenir. Souvenir packaging is a very exquisite, beautiful red box. But when experts happily open the box face to face in accordance with the country's custom, everyone's face looks very unnatural-inside is a golf cap, but the color is green. Finally, experts didn't sign the contract with them.

Analysis: The original intention of the businessmen is to play golf after signing the contract. However, "wearing green hats" is the biggest taboo of Chinese men. Experts didn't sign contracts with them, not because they "scolded" them, but because the businessmen were too careless about their work, and don't have a comprehensive understanding of Chinese culture. They can't hand over tens of millions of dollars in projects to them.

Case 4

Once a foreigner praised a Chinese girl student who majored in English "Your oral English is excellent, and quite fluent." But she immediately replied: "No, no. My English is quite poor". Moments later the foreigner found the skirt the girl was wearing very beautiful. She remarked: "The dress looks really nice on you". Again the Chinese girl demurred, "No, no. This is an ordinary dress. I got it cheaply". The foreign teacher was puzzled at these unexpected responses.

Analysis: From this case, we can find that under the influence of traditional Chinese culture, Chinese are more restrained and modest in their daily lives. Therefore, Chinese often say, "No, no, over praised" when they praised by others. But foreigners are very confident in their personality. When they are praised, they often accept others' praise frankly and respond politely: "Thank you".

Case 5

Once upon a time a monkey decided to leave the forest and explore the great, wide world. He traveled to the city and saw many strange and wonderful things but finally he decided to return home. Back in the forest his friends and relatives gathered around: "Well". They cried, "What did you see"?

"I saw buildings made of concrete and glass. Buildings so high that they touched the sky", said the monkey. And all his friends and relatives imagined glass branches scratching the sky. "The buildings were full of people walking on two legs and carrying briefcases", said the monkey. And all his friends and relatives could almost see the people running along the branches with their tails wrapped firmly around their briefcases (J. Brick, 1995).

Analysis: In the story, the monkeys who leave the forest to go to the outside world have different parts of the cognitive content of the monkeys who have been in the forest, so their understandings of outside world are also different. For example, monkeys who have been in the forest do not have an understanding of buildings and people in their cognitive content. Therefore, monkeys' understanding and their understanding of buildings are different.

\section{Difficulties Concerning Culture Teaching}

\section{The concept of culture is broad and the content is hard to determine.}

"There is an unclear concept that what culture is introduced in foreign language teaching" (Lin, 1996). Culture is a very broad concept. Therefore, many scholars and educators have different understandings and definitions of what culture is. Up to now, there are hundreds of definitions of culture. For instance, "Today, culture should be regarded as a collection of distinct and distinctive characteristics of the spirit, material, knowledge and emotion of a society and social group. Besides art and literature, it also includes lifestyle, human rights, value system, tradition and belief" (R. Williams, 1980). And D.Paul Schafer once said: "An organic and dynamic entity which is concerned with the ways in which people observe and interpret the world, organize themselves, guide their actions, promote and enrich their lives, and how to establish their position in the world" (1998). Furthermore, "Culture is not the privilege of the elite, and it should be universal and popular, involving all aspects of our social life" (Lu, 2006).... All these definitions show that culture is a very broad and complicate concept. Culture includes all aspects of human social life. Different countries also have different cultures. Furthermore, with the development of economic globalization, the definition of culture becomes more complex, and the concept of culture becomes more difficult to define. Different scholars have different understandings and definitions of it, which determines that the content of culture-related teaching is also difficult to determine. Moreover, with the rapid development of economic globalization, cultures of different countries are also interacting. Every country is more or less influenced by other countries, which further increases the difficulty of choosing cultural content.

\section{Lack of supplementary teaching materials and required teaching staff}

At present, we do not have a set of scientific and systematic textbooks with rich and systematic cultural knowledge. Most of the current textbooks we can see are compiled with "language-centered" and "grammar as the skeleton" (Zhang, 2003). Nowadays, there is a great lack of textbooks for cultivating students' cultural knowledge. "To teach a foreign language well, a foreign language teacher is required to master certain cultural knowledge while mastering the language" (Liu, 1999). In English teaching, it is very demanding for teachers to cultivate foreign language talents with cultural knowledge, which requires teachers not only to have a solid language foundation, profound cultural accomplishment, a comprehensive understanding of the language, but also to have a strong cross-cultural communicative competence. However, most primary and secondary school English teachers do not know much about cultural knowledge, and a small number of primary and secondary school English teachers have the opportunity to study abroad for further cross-cultural training, This also determines that cultural knowledge of English teachers' in China is far from comprehensive.

\section{Lack of evaluation criteria}


Evaluation is an important part of English teaching. Without corresponding evaluation methods and evaluation criteria, teaching is hard to conduct. Nowadays, Improving of cultural literacy has been included in the curriculum requirements, but cultural knowledge has not been included in the examination. Currently, foreign language testing is still focusing on more easily assessed aspects of language such as grammatical accuracy and vocabulary knowledge rather than on communicative competence. Therefore, the time for culture training and teaching resources preparation are limited. Under the tremendous pressure of entering a higher school, teachers will naturally abandon cultural teaching for various considerations, and then put more emphasis on explaining grammar points, language points and guiding students to pass various examinations. This is what Penner said, "For many Chinese teachers of English, the aim is to provide the grammatical and vocabulary knowledge so that the students can successfully pass the many exams they must take" (J. Penner, 1995). Therefore, cultural teaching of English is hard to conduct in schools of China, because both teachers and students are facing the heavy pressure of entering a higher school.

\section{ApPlication of Cultural Models to Primary SchoOl}

From the above analysis, we can see the cultural teaching is an important part of English teaching. We should realize that teachers should lay emphasis on both language teaching and cultural teaching. In this part, I will provide some strategies which are helpful for cultural teaching and provide a case of cultural teaching.

A. Strategies of Incorporating Culture into English Teaching
1) Providing information
2) Problem-solving
3) Students-centered
4) Culture-centered

\section{B. Teaching Case of Cultural Models}

The teaching material is taken from PEP, Grade 4, and unit 5. The following class is built up from a conversation and the main idea of the conversation is about two persons who have dinner with different table wares.

In this conversation, there is a boy who prefers to eat by knife and fork, while a girl advises him to try chopsticks. We can see the different diet habits between the two characters. Therefore, there is a cultural point- the different eating habits between Chinese and Westerners. This class will adopt cultural models theory to help students have a better understanding of western diet culture.

Teaching objectives:

Knowledge Objectives:

By the end of the lesson, students should be able to:

1) identify the words, phrases and sentences related to table wares, such as chopsticks, knife and fork.

2) use the words, phrases and sentences related to food, such as beef, rice, vegetables, knife, fork.

Ability Objectives:

By the end of the lesson, students should be able to:

1) describe theirs' catering experiences.

2) use knife and fork correctly.

3) differentiate the eating habit between Chinese and Westerners.

Moral Objectives:

By the end of the lesson, students should:

1) respect different cultures.

2) form cultural awareness of foreign country.

Teaching aids: multimedia, knives, forks, spoons, cards of food, drinks, etc.

Teaching procedures:

Step 1 The teacher will ask students to listen to the conversation, and ask students to discuss 2 questions, and then the teacher will lead in the western diet culture through different eating habits between the two characters from different countries.

1. Why does the boy prefer a knife and fork to eat?

2. Why does the girl advise the boy to try chopsticks?

Step 2 The teacher will ask students question about the differences between Chinese and Western diet culture from their own experience. The teacher will ask the students to write down the answers about the differences between Chinese and Western diet culture

Step 3 The teacher will show a short video of the conversation to students, and ask them to observe the food, the table wares, the environment, and the characters' behaviors in the short video.

Step 4 The teacher will firstly show a short video about a traditional Chinese dinner to the students, and secondly show them a western dinner to students, and ask students to find the differences between traditional Chinese dinner and western dinner, such as the food they eat, the tableware they use, the diet environment, the characters' behaviors and so on, and then invite students to answer the questions about the differences between traditional Chinese dinner and 
western dinner.

Step 5 The teacher will invite some volunteers to simulate a traditional Chinese diet environment, and invite some volunteers to simulate a western diet environment. In this part, the teacher will give out the prepared teaching aids to performers, and ask them to set up the diet environment based on what they have just seen in the video. Then, the teacher should invite more students to simulate the "dinner" several times according to their understanding of western table manners.

Step 6 After the activity, the teacher will ask students to discuss the differences between Chinese diet culture and western diet culture in groups, and write down their answers, and then share the answers in class. Finally, the teacher will make a summary about the class and then make some other supplements.

\section{Case analysis:}

This class is built up from a small cultural point - the different eating habits between Chinese and Westerner. In this class, students can not only learn about different diet cultures, but also experience the different diet cultures. Furthermore, in this class, students' cross-cultural awareness about different diet cultures can be greatly cultivated in the compared environment.

First of all, in this class, the activity begins with listening to the conversation, and it is aims to catch the attention of the students. And then the teacher puts forward two questions about why the two speakers prefer different tableware like: why does the boy prefer a knife and fork to eat? Why does the girl advise the boy to try chopsticks? This is aimed to make the students get involved in the class. Then, the teacher shows a video of the conversation to students, and asks them to observe the characters' behaviors in the conversation, the different diet environment, the different food and so on. Next, the teacher shows a short video about a traditional Chinese dinner and a western dinner to students, and asks students to find the differences between traditional Chinese dinner and western dinner. It is aims to guide the students realize the differences between traditional Chinese and western culture, and then find the differences between traditional Chinese dinner and western dinner on their own. And then, the teacher will invite some volunteers to simulate two different diet situations with prepared teaching aids, which can make students recall what they saw in videos and guide the students to memorize what they saw in the videos. Finally, in the part of summary, by reflecting western eating habits and Chinese eating habits, and comparing the Chinese and Western diet again, students will realize the differences between western diet culture and Chinese diet culture. Therefore, students' cross-cultural awareness will be unconsciously developed and strengthened.

\section{CONCLUSION}

Training of cross-cultural awareness is an important part of English teaching in primary school. This paper mainly based on the theory of cultural models, and analyzed the advantages of the cultural models on the cultivation of cross-cultural awareness of the primary school students. The present situation of primary school English teaching needs improving, and the implication of cultural models will be of great helpful for it. The paper summarizes how to apply cultural models to primary school English teaching and give a teaching case for example. However, there are some shortcomings in this paper. Firstly, the application of cultural models in primary school is only a hypothetical one, and there is no corresponding empirical research to prove it. Furthermore, this paper is a preliminary exploration of the application of cultural models to English teaching in primary school which doesn't describe the detailed rules of assessment. Therefore, teaching practice activities should be carried out and assessment methods should be explored in the future research.

\section{REFERENCES}

[1] Chen Xiaoqing. (2017). Theory and method of cultural model. Philosophy of Science and Technology Research, $34,4,108$.

[2] D.Paul Schafer. (1998). Culture: Beacon of the future. Twickenhan: Adamantine Press.

[3] English Curriculum Standard for Compulsory Education. (2011). Beijing: Beijing Normal University Press.

[4] F. Ungerer\&HJ. Schmid. (2008). An introduction to cognitive linguistics. Beijing: Foreign Language Teaching and Research Press.

[5] J. Brick. (1995). A handbook for intercultural communication. Sydney: Allen and Unwin.

[6] Lin Ruchang. (1996). Three levels of foreign language teaching and three levels of cultural introduction. Foreign Language World, 4, 1-6.

[7] Liu Runqing. (1999). College English Teaching. Beijing: Foreign Language Teaching and Research Press.

[8] Lu Yang. (2006). Cultural definition analysis. Journal of Jishou University of Science and Technology, 27, 151-154.

[9] J. Penner. (1995). Change and conflict: Introduction of the communicative approach in China. TESL Canada Journal, 12, 1-2.

[10] R. Williams. (1980). Problems in materialism and culture. London: Verso Editions.

[11] Xu Jianhua. (2003). Cultural model theory of cognitive linguistics and second language teaching. Zhejiang: Zhejiang University Press.

[12] Zhang Youping. (2003). Understanding of language teaching and culture teaching. Foreign Language World, 3, 41-48. 
Xin Ma was born in Chongqing, China in 1993. She received her Bachelor degree in English from Yangtze Normal University in 2017.

She is currently a postgraduate student in the School of Foreign Languages, Chongqing Normal University, Chongqing, China. Her research interests include English language teaching and American literature. 